Noah Roderick*

\title{
How to be a Realist about Similarity: Towards a Theory of Features in Object-Oriented Philosophy
}

https://doi.org/10.1515/opphil-2018-0024

Received August 14, 2018; accepted October 8, 2018

\begin{abstract}
This essay calls for an independent theory of features in object-oriented philosophy. Theories of features are in general motivated by at least two interconnected demands: 1) to explain why objects have the characteristics they have, 2) to explain how regular divisions in those characteristics can be intuited. While a theory of universal properties may be the most internally consistent means of addressing these demands, an object-oriented metaphysics needs to address them without a concept of shared features. This means that regular divisions of invariant features and our intuitions of them cannot be explained by the repetition of self-same characteristics or natural laws. They can instead be explained by the immanent repetition of similar features. However, this requires a new, radically aesthetic understanding of what it means to be similar in the first place, one in which similarity is an emergent process rather than a state of affairs existing between resembling particulars.
\end{abstract}

Keywords: universal properties, tropes, features, object-oriented ontology, similarity, aesthetics, materialism, repetition, Plato, Edmund Husserl, Bertrand Russell, Graham Harman

\section{Introduction}

It is safe to say that continental philosophy and continental-adjacent fields are in the midst of a turn towards realism. Thinkers in those areas are suddenly liberated to talk about the things that had previously been left to science and analytic philosophy. This freedom to explore reality without first passing through a linguistic filter has understandably led to a lot of meditations on objects themselves, relations between objects, and networks of objects. Yet in this rehabilitation of metaphysics, there has been very little attention paid to one of the most basic metaphysical concerns: why are there regularities in the world? This question is the very link between metaphysics and physics, philosophy and science. For example, if hydrogen and oxygen atoms only sometimes had the chemical valences they have-if the $\mathrm{H}_{2} \mathrm{O}$ molecule did not have the polarization density it always had-then water could not act like water for other substances with which it interacts. Absent a theory of apeironic matter repeating itself across inexplicably finite topological configurations, the question of regularity becomes a wicked problem which forces us to another difficult question: is it possible to be a realist about similarity?

It is again understandable that these questions have not been enthusiastically taken up in the continental turn towards realism, first of all because talking about regularity in the world carries with it the baggage of nature. Nature is a top-down (even anthropocentric) conception of reality, and there is no room for such a unifying term in ontologies which begin locally at the object or network level. Second, similarity and the categories we build from observed similarities appear to be a subordination of all reality to human experience. If there is a unifying ethos for this new brand of realism-speculative realism-it is the rejection of Kantian correlationism, the notion that we cannot think of reality outside of the tragic split between human subjects and objects. One of the things Kant inherited from empiricism was the belief that similarity

*Corresponding author: Noah Roderick, Örebro University, Sweden; E-mail: Noah.Roderick@oru.se 
belongs to the experience of the human subject. It seems right, then, that if we are to make an exit from the correlationist circle, we should take similarity with us.

In order to talk about similarity, regularity, and the means of apprehending regularity, it is necessary to explore the topic of features ${ }^{1}$ on its own terms, since features play a causal role in similarity and difference amongst particulars. Among the varieties of thought associated with speculative realism, object-oriented ontologies ${ }^{2}$ have the most to say about features as such. The subject of features is particularly salient in Graham Harman's object-oriented philosophy, a metaphysics that includes both relational and nonrelational features in its mechanics of causality. However, even with the prominent position Harman affords features in his model of the object, a fully mature object-oriented theory of features needs to engage with and distinguish itself from the existing field of theories about features. In this case it means an engagement with analytic philosophy, since that is where the most fruitful thinking about features has occurred in the last century. Harman himself has likened his conception of object qualities to tropes, ${ }^{3}$ a notion of features developed in analytic philosophy as a middle ground between the problems of universal properties and the silence of nominalism. And part of the work of this essay will be to draw out those crucial differences between universals, tropes, and object-oriented features.

Intuitively, a correspondence between trope theory and object-oriented philosophy makes sense. Like object-oriented features, tropes are immanent to their particulars. This immanence of features in both objectoriented philosophy and trope theory stands in stark contrast to theories of universals in which particulars participate in properties which transcend those particulars. And while a theory in which properties exist independently of the particulars that instantiate them may seem hopelessly anachronistic, universalism solves the two problems that motivate a theory of features in the first place: the problem of what causes particulars to have the characteristics they have, and the problem of how we can intuit various characteristics from a field of particulars. Plato, famously, had a ready response to both problems with his participation of the many in the one: particulars can have different sets of features because they resemble by virtue of originary forms to which we have access. On the other hand, trope theory's immanent concept of features demonstrates that the features of particulars can inhere with particulars themselves and that those features resemble so that their particulars can interact in regular ways. But trope theory suffers from a fatal weakness in that it is unable to explain regularity in a way that allows for the immanent production of difference. Thus it is unable to offer an explanation for how immanent regularity is caused in the first place. The problem resides in the widespread definition of tropes as resembling exactly. In trope theory, for example, a red triangle and a red square have the feature of redness because the red of the triangle and the red of the square and the red of anything else resemble exactly; and this exact resemblance makes the trope red different from the trope blue, the trope white, etc. This view of similarity, I argue, is nothing other than partial sameness between particulars, and without a theory of universals there is nothing to cause this sameness in the first place. In other words, similarity provides a path to a theory of immanent features, but the whole project is undermined without a theory of immanent similarity. And insofar as object-oriented philosophy adopts the discourse of trope theory to explain features, this causal dead end in the latter becomes a trojan horse for the former.

The solution to this impasse is to recover similarity as a purely aesthetic concept. Which is to say that similarity emerges in an object's sensual experience of another object. This solution comports well with object-oriented philosophy's central claim that causality in general is aesthetic. My argument is that objects passively imitate (conform to) the objects they intend, and that the new objects which emerge from those intentions are mimetic repetitions of the intentional act. In its truly aesthetic sense, similarity is not a state of affairs but a becoming. And in this sense of becoming, similarity can account for regularity and the production of difference where exactly resembling tropes cannot.

1 In this essay, I will be using features as a generic term along with others which correspond to specific schools of thought, such as universal properties, tropes, and qualities.

2 It was Levi Bryant who coined the term object-oriented ontology. Bryant himself uses it as an umbrella term for the different strains of metaphysics which put objects at their center. Bryant differentiates those strains that begin with Harman's immaterialist metaphysics with the term object-oriented philosophy. This seems just as good of a distinction as any, so it is what I will be employing throughout this essay.

3 Harman, Quadruple Object, 30. 
Having addressed the topics of regularity and difference, the essay turns to the other prime motivator for a theory of features, which is intellectual access. This would seem to be a fool's errand in object-oriented philosophy since its ontology denies direct knowledge about an object or its essential features. However, even with respect to the impossibility of direct knowledge, object-oriented philosophy in its current form leaves one object-to-object relationship open only to beings with an intellect: the intuition of an object's eidetic or invariant features. This loose end causes uncertainty not just about an epistemology of objects; it also potentially undermines object-oriented philosophy's reliance on a flat ontology. As a corrective, I suggest a way in which any object may experience invariance through the repetition of similarity in a field of intentional experience. Experiencing invariance is not the same thing as the intellectual intuition of an object's invariant features, but it is, I argue, a necessary precondition for it. Armed with an understanding of the ontological conditions in which regularity and intuition are possible, object-oriented philosophy surpasses trope theory in its ability to offer a consistent theory of immanent features.

\section{On universals}

Despite their seeming incompatibility with realism, theories of universal properties remain the most durable and consistent approach to the problem of features. Indeed, property universalism continues to set the terms of debate for contrasting approaches to features. The best and most familiar place to begin a discussion of universal properties is with Plato and his modern counterpart, Bertrand Russell. Differentiated, transcendental forms are primitive as far as Plato is concerned, and they include physical forms like wingedness, but also moral concepts like justice, all of which can be gathered as primitive ideas and discovered as truth. We have access to primitive ideas through memory and (imperfect) mental representation because our souls had direct access to them before being instantiated as particular bodies. This is how Socrates gets Meno's uneducated slave to tell us something true about geometrical ratio. It is only thanks to Russell that philosophers now speak of universals instead of the ideas or ideal forms found in the Platonic tradition. It's easy to think that Russell trades ideas in for universals as a way of keeping the concept while jettisoning any notions about souls and a transcendent mind to whom those ideas might belong. Russell does lodge a complaint against the mysticism of ideal forms, but that is by no means his main objection. He is far more concerned with the constraints that notions like ideas or forms put on universals. For instance, when it comes to a priori knowledge, Russell accuses Kant of trying to have it both ways: a priori knowledge of an arithmetical fact like $2+2=4$ is universal to human knowledge because human subjects have a priori knowledge of time, space, causality, and comparison. The seemingly universal ability to synthesize two instances of two is part of the nature of the subject. Kant's flaw, according to Russell, is turning the world into the subject's interior:

The thing to be accounted for is our certainty that the facts must always conform to logic and arithmetic. To say that logic and arithmetic are contributed by us does not account for this. Our nature is as much of a fact of the existing world as anything, and there is no certainty that it will remain constant. It might happen, if Kant is right, that tomorrow our nature would change so as to make two and two become five. ${ }^{4}$

Thus trying to pin universals to mental or physical particulars does not work because mental and physical particulars can change or get destroyed. The mind cannot relativize anything that is not already relational. And this, finally, is why Russell thinks the association of universals with forms or ideas is too limited, observing that "Even among philosophers, we may say, broadly, that only those universals which are named as adjectives or substances have been much or often recognized, while those named by verbs and prepositions have usually been overlooked." ${ }^{5}$ Russell therefore opens the field of universals up to prepositional relations like "north of London" in addition to adjectival relations like "is white." It is not

4 Russell, Problems of Philosophy, §8.

5 Ibid., $\S 4$.

6 Ibid. 
that Russell wants to crowd the pitch with universals; rather he wishes to call attention to what universals are, that is relations which are independent of thought or particular instantiation. The strength of this argument is that relations cannot be said to exist in the world like red cars, red apples, and red lights do, and so are capable of being repeated as the same, even if, for instance, all red things ceased to exist.

Here we hit upon two things that universal properties need in order to fulfill their functions of regularity and identity: repetition and some manner of sameness. For example, when I pour club soda and whiskey into a glass, the resulting cocktail would appear to share the same properties of fizziness and wateriness with the club soda which was poured in with the whiskey. If the same properties of fizziness and wateriness were repeated from the club soda to the cocktail, then we could say that the club soda made direct contact with the whiskey, and that that direct contact caused the cocktail to be. Under universalism, the cocktail is nothing different from the difference between the repeated properties of the club soda and the repeated properties of the whiskey. The being of the cocktail, in other words, would be the zero remainder of the difference between the properties of the club soda and whiskey. Those properties pour themselves into the zero remainder of the cocktail's being, meaning that there is nothing mediating their contact. Thus direct contact is the repetition of the same. A further conclusion to be drawn from this is that repetition in general is contact in general. This insight will give us a way of talking about indirect contact as well.

\section{Trope theory and object-oriented philosophy}

Insofar as reality is contained within self-mediated objects which directly contact neither an underlying substance (e.g. apeironic notions of matter) nor other objects, there can be no room for unified properties repeating themselves across discretely existing things. In Harman's formulation of object-oriented philosophy, an object's reality lies at the tensions of four poles: 1) the real object that withdraws beyond any direct access; 2) the sensual object which is in direct contact with another real object; 3) sensual qualities which occur at the surface of the sensual object, and 4) an object's real qualities, which are necessary for both the sensual and real objects but which, like the real object itself, withdraw from direct contact. Insofar as this is a 'quadruple object,' Harman gives Edmund Husserl credit for getting three-fourths of the way there, as Husserl understood that sensual (or intentional) objects are something other than just an aggregate of accidental features, that the sensual object cannot exist outside of a tension with its real qualities (eidos), even as those qualities are withdrawn from the realm of direct experience. ${ }^{7}$ Harman, however, departs from Husserl on the issue of an object's features in at least two significant ways. For one, Harman does not think, as Husserl does, that the eidetic features of an object can be accessed through categorical intuition any more than they can through the senses, even if the intellect is the way in which we might intuit those features. ${ }^{8}$ Second, Harman claims that "Husserl speaks of real qualities in generic terms, such that a certain shade of green can be embodied in many different particular objects [...]." In other words, there is something of the universal in Husserl's version of eidetic features which would be incompatible with a realist and object-oriented ontology.

Harman's objection to epistemic access will be addressed later on in this essay, but we must first look at the question of what these qualities actually are. Harman definitively asserts that an object's features are "always individualized by the object to which they belong." ${ }^{10}$ And while affirming the anti-universalist position of object-oriented philosophy, he goes on to equivocate the qualities of objects with tropes in analytic philosophy. Harman does not seem to revisit this identification, but it deserves a closer look if for no other reason than that the issue of what tropes are and how they are possible is far from settled in the analytic tradition itself.

The modern conception of tropes in metaphysics, which is widely credited to D.C. Williams's 1953 essay, "Elements of Being," emerges as a useful mediation in the debate between universalists and nominalists.

7 Harman, Quadruple Object, 27-29.

8 Ibid., 28.

9 Ibid., 30.

10 Ibid. 
W.V.O. Quine's so-called "ostrich nominalism"11 in particular ceded metaphysical explanations of type and regularity to epistemology, calling for an ontological commitment to nothing but particulars. Quine's nominalism does sidestep some of the thorny problems of universals, such as negative and disjunctive properties, not to mention the unenviable task of trying to justify abstract properties that endure beyond their particular instantiations. But this sort of pure, uncut nominalism also leaves Metaphysics with very little to say about metaphysics. The trope theorist's solution is to commit to the idea that resemblance between particulars is neither an abstract property nor a mere function of the human tendency to predicate particulars. As Keith Campbell puts it:

Trope theory is first and foremost a theory of the ontic constitution of the cosmos. It is a scheme to account for the patterns of variety, resemblance and order to be found there. That this world is a world of tropes is a thesis that advances quite independently of the existence of human thinkers that have developed language. ${ }^{12}$

Campbell's definition certainly aims to secure trope theory's place as a realist metaphysics, which is why trope itself is such a curious choice of term to lead with. In common usage, trope is associated with aesthetics, and it's often used synonymously with theme and motif. All of these terms connote a repetition of similarity, whether it be the repeated embedding of similar phrase in a piece of music or the echo of certain hues that suggest a particular emotion in a painting. No doubt it is exactly this aesthetic connotation that appeals to Harman, who, after all, claims that causality itself is aesthetic. And indeed, I would argue that it is exactly the failure to take aesthetic causality seriously that condemns trope theory to merely being a stopgap measure against the challenge to realism posed by nominalism.

The important work trope theory does is to exclude any features that a particular object could not possibly have. For instance, no single lake could have wetness in general. A particular lake has only its own expression or style of wetness (again, we're sourcing these descriptions from the discourse of aesthetics). The difficulty trope theory runs into in this instance is how to account for the lake having its own style of wetness in the first place. In other words, what particularizes a particular? We have already seen that this is not a problem for the universalist because the very notion of a universal is that which distinguishes itself from its many instantiations. Trope theory has largely relied on one of two options to sort out the problem, each of which comes with significant shortfalls. ${ }^{13}$ The first option is to try and preserve the one-many dialectic of universalism by opposing a substratum of bare existence to the tropes it joins together. But trope theory cannot so easily oppose being to existence as Russell is able to do with his universal relations, and as such, this bare particularity begins to look itself like a trope. The only two exits from this point are through monism or, again, universals. The other option-the widely favored option-is to downgrade objects to the status of trope bundles. The problem here is that once you demote the object to bundle status, you have lost your right to say that tropes are particularized features, or features in the style of something. Taking away the object's existence, it seems, takes nothing away from its insistence.

Trope theorists, however, are still able to synthesize particularity out of internal relations within trope bundles. ${ }^{14}$ The liver-kidney relation is always a popular one amongst analytic philosophers. In this case, it would hold that an animal which had the trope of beliveredness would necessarily have the trope of bekidneyedness, since there are no animals who have livers who do not also have kidneys. And those sorts of internal relations would proliferate until we get to the particularity of one particular animal. But it is not at all clear that such necessary internal relations would get you any further than natural kinds, since not all tropes that a particular expresses are necessary for a particular to exist, even if they are necessary to the particular's particularity. The necessary compresence of tropes gets us to the kind of regularity that universals offer, but with respect to particularity, it can take us no further than the level of natural kinds. And sharing a natural kind is no more compatible with trope theory than is two lakes sharing the property of wetness. Thus we are left with a situation analogous to Heisenberg's uncertainty principle in which the

11 Armstrong, Nominalism, 16.

12 Campbell, Abstract Particulars, 24.

13 Edwards, Properties, §3.5.

14 Ibid. 
more known about a particle's position, the less known about its momentum, and vice-versa. In this case, the more we try to pin down an object's essential features, the less we can know about its eidetic features, and vice-versa.

Unlike trope theory, object-oriented philosophy anticipates this evanishing axis of existence and essence with its notion of the withdrawing real object, so that the features which, for example, make Stockholm an existing city and the features that make it essentially Stockholm are indistinguishable. Those features are not just indistinguishable to the observer's intellect but to the city itself. And yet, the withdrawing real object preserves particularity without collapsing into a bare substratum because the real object is capable of making direct contact with sensual objects in its own style. ${ }^{15}$ Since it is limited/able to make contact with whole sensual objects rather than there being direct contact between real features (as we typically imagine contact between inanimate objects to look like), contact is a sensuous, aesthetic experience, and relations between features are therefore never exactly repeatable. There is no need to make a choice between selfsame properties (i.e. universals) and self-same bare existence.

\section{Similarity's anti-realist inheritance}

Trope theorists are forever condemned to making a choice between self-same properties and bare existence because they are unable to integrate the aesthetic nature of a trope into reality. At issue here is what exactly it means to resemble or to be similar. Having no problem with the idea of repeating, self-same properties, universalists can demand of trope theorists to explain regularity without some underlying uniformities in the universe. This demand, in fact, consists of two challenges: one about the slipperiness of resemblance, and the other about the relationship of resemblance becoming itself a universal. As I will attempt to show, both challenges can be met by taking the aesthetic nature of tropes seriously, which means taking similarity on its own terms.

When we speak of similarity as in the similarities between tropes which make them tropes in the first place, we are already speaking about relations. What is left to decide is whether a relationship of similarity is aesthetic or if it is, for lack of a better word, actual. An aesthetic relation is given in experience; it is a matter of intensity and becoming. An actual relation is simply given; it is a state of affairs. If the similarity in a relation between objects with tropes is actual, then their similarity is a matter of extension and thus of degree. And indeed, Williams holds that the relationship is one of "exact resemblance."16 This means that whatever other tropes that particularize them may be, when a brick meets a concrete wall, they would already have their own instances of a hardness trope. Furthermore, hardness is only a trope because the brick and the wall and anything else that was already hard resembled each other exactly in that respect. A watermelon-flavored Jolly Rancher candy also has the trope of hardness (it's a hard candy), but it further resembles the brick in its redness and rectangularity. If tropes are characterized by discrete instances of exact resemblance, then we would be tempted to say that the red brick is more like the Jolly Rancher than it is like the concrete wall. But of course as a way of determining the brick's essential nature, this wouldn't feel right, so we would have to say either that overall similarity is determined by a single, more critical similarity or that the hardness of the brick is more similar to the hardness of the concrete wall by degree. The first option, "dictatorial" ${ }^{17}$ similarity, is problematic because it means that some tropes are more essential than others. It is not at all clear if this means that certain tropes would be more essential in all cases or if certain tropes are more essential in certain relations of similarity. If some tropes are more important in all cases, then those essential tropes at least would not need to be embedded in relationships of exact resemblance because their causal powers would be present in each instance. Such tropes, in other words, would function as universals. Otherwise, the dictatorial similarity would be a contingent phenomenon, emerging only in particular, comparative relations. In such cases, similarity would not be anything real to the objects, but a

15 Harman, Quadruple Object, 76.

16 Williams, The Elements, 59.

17 Morreau, "It Simply Does," 477. 
matter of selection by the one doing the comparing.

Leaving similarity as a matter of degree brings with it even more problems. Again, for trope theory, objects resemble by virtue of their tropes resembling. It is possible that a watermelon Jolly Rancher has more degrees of similarity with a red brick than the red brick has with a concrete wall. But if the wall is more similar to the brick with respect to a trope such as degree of hardness, then-problems with the dictatorial trope aside-we will have to include degrees of dissimilarity into our scheme of tropes. In which case, dissimilarity is at least as determinative of particularity as is similarity. Finally, degrees of similarity leaves us open to Nelson Goodman's transitivity problem, ${ }^{18}$ in which everything becomes similar to everything else (e.g. the Jolly Rancher becomes similar to the concrete wall), rendering similarity an empty concept altogether.

Thinking of an object's features in terms of resembling tropes is a good way to preserve the particularity of objects and to explain regularity in the world without falling back upon ideals or abstractions such as universals. However, defining similarity as exact resemblance between tropes renders the entire concept incoherent, especially when particular objects are reduced to bundles of tropes. If particularity is a relation between those tropes which constitute the particular, and if tropes are discrete instances of exact resemblance, then the resemblance between particulars (which would account for regularity) is a matter of quantizing exact resemblance, and so there is no good ontological reason for a brick to be more like a concrete wall than it is like a watermelon Jolly Rancher. Rejecting that, the trope theorist must talk about overall similarity. And the only way to account for overall similarity and exact resemblance in the same breath is to posit a dictatorial resemblance, which is really no different than accepting universals, since dictatorial similarities must be critical before entering into any relation of similarity. Nonetheless, I contend that overall similarity is the best way to account for regularity, but in order to avoid falling into the twin traps of quantized resemblance and dictatorial resemblance, we must break with our inherited concept of similarity, banishing the notion of exact resemblance.

When we notice, for instance, that the watermelon Jolly Rancher we've just unwrapped seems like something else, the experience of the one seeming like another is sensuous and pre-theoretical. It is, in other words, an aesthetic experience. And it is at this moment of utmost superficiality that we grasp similarity for what it really is. As soon as we begin thinking that both the candy and a brick are red, rectangular, hard, etc., we are subjecting the experience to binary predicative logic. Thus the experience of similarity is analogue but the concept is digital. When the concept of similarity is applied to a relation, it is used to determine a sameness inhering in different particulars. Intellectual intuition gets pulled to one of two poles-same and different-like a piece of iron to a magnet. The nominalization of the term for similar with which Plato used to talk about the concept in Timaeus, ${ }^{19}$ Meno, ${ }^{20}$ and The Republic ${ }^{21}$ plainly reveals an inherited failing of the concept. A literal rendering of homoiottas would be 'sames-ness,' wherein same is semantically one but grammatically plural. The internal contradiction of the one in the many is solved by the dialectic of the universal and the particular, the ideal and the copy. But this is just kicking the can down the road a little. Take Socrates's exchange with Glaucon in The Republic regarding the three couches. ${ }^{22}$ In this scenario, the painter moves furthest from the couch's true form because he imitates just a look of the couch which was created by a craftsman, the idea of which was created by the god. Truth lies in the order of appearance; and imitation-that is, becoming similar-is nothing more than orders of multiplication. The craftsman may produce several copies of the god's one couch, the god needing to produce only one lest he himself make a copy. The painter, on the other hand, produces a copy of several looks of one of several couches:

\footnotetext{
18 Goodman, "Seven Strictures," 440.

19 Plato, Timaeus, 33b.

20 Plato, Meno, 80a.

21 Plato, The Republic, 596b.

22 Ibid., 596a-598c.
} 
Does a couch, if you observe it from the side, or from the front, or from anywhere else, differ at all from itself? Or does it not differ at all but only look different, and similarly with the rest? [...] Toward which is the painting directed in each casetoward imitation of the being as it is or toward its looking as it looks? Is it imitation of looks or of truth? ${ }^{23}$

The painter is the ultimate imitator because he imitates what is already rendered similar. The painting is a repetition of a repetition. The repetition the painter is imitating is a sensuous experience, which is several looks of one thing. Since the several looks in the one experience is not really a one-to-one correspondence either to the thing itself or to the idea of the thing-since it is between the one and the many-the experience the painter is imitating is outside of the truth. The imitator's imitation includes the excluded middle, violating the opposition of being to not-being. What we can say then is that homoiotas and our inherited concepts for similarity have been robbing themselves of their own meaning. Perhaps similarity was always an aesthetic concept imprisoned by its logical denotation. Exact resemblance is either a redundancy or an oxymoron. Therefore, if the causal features of objects can be understood as tropes, then trope must be understood with fidelity to its aesthetic connotations, along with theme and motif.

\section{Mimetic repetition and the production of difference}

The difference between a reality with tropes and one with universal properties is that in the former, features do not transcend their objects. If there are differences and similarities between objects upon which regularity supervenes, it is because those differences and similarities reside first with objects themselves, not with their features. This sort of object-first identity cannot occur if particular objects are partially the same or partially different, which are two sides of the same coin under the term of exact resemblance. I have already argued that the repetition of the same property in universalism is what direct contact looks like, but in object-oriented philosophy, real objects never make direct contact. Contact and therefore causation is indirect so that a real object only makes contact with a sensual object within an aesthetic experience. Since contact is a kind of repetition, indirect contact is not a repetition of the same but a repetition of the similar, a mimetic repetition.

Writing about the critical possibility of object-oriented philosophy in the fine arts, Harman enjoins his readers to reconsider the value of mimesis. In doing so, he uses the peculiar metaphor of a method actor:

My claim [...] is that art is mimesis, but in the theatrical sense of method acting, rather than the productive sense of fabricating imitations. The artist imitates not by producing copies of external things, but by becoming external things. ${ }^{24}$

While it is true that, elsewhere, Harman bristles at absolutist anti-anthropocentrism by arguing that art does not exist without humans, ${ }^{25}$ there seems no reason why this claim about mimesis and art should not be extended to objects in general, especially given Harman's own system of vicarious causality. Again, in Harman's formulation, real objects do not enter into direct contact. Relations between real objects are mediated by an intentional or, in Harman's terminology, a sensual object. The real object translates or distorts the sensual object in its own style. The real object behind the intended object is not affected in this particular relation (though overlapping relations are possible), so contact is always asymmetrical. ${ }^{26}$ To say that the affected real object translates or distorts the sensual object into existence is not inaccurate; however, we could also frame this aesthetic experience in Aristotelian terms of $p a t h \bar{e},{ }^{27}$ which is a body's capacity to be affected passively. In this case, what the affected real object is doing is productively conforming to or imitating the sensual object, just as the sitter conforms her body to the sensual couch. But there is, for Harman, even more going on in such intentional relationships than this. The intentional relation is itself a new object which is composed of the affected real object and the sensual object, thereby

23 Ibid., 598a-c.

24 Harman, "Materialism," 94.

25 Harman, Dante's, loc. 3336.

26 Harman, Quadruple Object, 75.

27 Aristotle, De Amina, 403a. 
making the aesthetic experience ontically productive. ${ }^{28}$ Note, however, that neither the features of this new object nor the new object itself are syntheses of the affected real object and the sensual object it intends. Object-oriented reality operates under a strange arithmetic in which multiplication exists without addition. Synthesis is impossible in object-oriented philosophy since it would mean multiple objects sharing the same real features or directly contacting each other's real features, leaving us with either universals or exactly resembling tropes, respectively. Instead the new object imitates the imitating/affected real object. The new object is the double imitation that Plato warned us about. Indeed Socrates acknowledges the wizard imitator's capacity for novelty because unlike the carpenter who only imitates the real couch into existence, the imitator can imitate anything into an albeit illusory existence.

Let's return to Harman's theatrical metaphor and flesh it out with the well-known method actor, Daniel Day-Lewis. If on-set talk is to be believed, Day-Lewis takes his method acting to a near absurd level of seriousness, never breaking character for the duration of the role. For instance, in his last film before retiring, The Phantom Thread, Day-Lewis reportedly learned his character's trade of dressmaking. DayLewis's character, Reynolds Woodcock, is a real object whose sensual form Day-Lewis imitates. The enacted role itself is a new object with the appearance of Day-Lewis becoming Woodcock. Here we have a double imitation-a repeated repetition-which, far from illusory or fleeting, will probably outlive the actor Daniel Day-Lewis. The strange thing is that now the character, the actor, and the role all have a feature we would call dressmaking ability, but none of those dressmaking ability features are capable of exactly resembling one another. If, for example, you happened to be close enough friends with Daniel Day-Lewis, and you asked him very nicely, he might very well make a dress for you. His performed role of Reynolds Woodcock on the other hand could do no such favor. If the performed role were merely a synthesis of the character and actor (emerging in that order of appearance), then the role should be perfectly able to make a dress for you. Instead what we have is a real and durable divergence between them; we have the production of difference. Accepting object-oriented philosophy's account of vicarious causation, there is no reason to think that this method acting mimesis wouldn't occur for objects and their features in general.

By understanding the emergence of difference as being one and the same with localized mimetic repetition, we have gained a significant advantage over trope theory, one which theories of universals already enjoy: being able to account for difference in the first place. Under Platonic universalism, the particular can participate in multiple universals since it itself is not self-identical in the way a universal is identical. If a particular is not self-identical, then difference is already baked into its being. Furthermore, Russell's inclusion of, for instance, prepositional relationships into the realm of universals ensures that universals themselves do not collapse into a single universal (e.g. the Good). For example, if a particular can participate in north-of, it can also participate in south-of. On the other hand, by insisting that that particulars resemble exactly in their tropes and that there are tropes because particulars resemble, trope theory fails to make a decision on whether resemblance originates in some more fundamental differences in the universe or if the pure multiplicity of particulars itself causes different tropes; in which case it becomes unclear as to how tropes play a causal role with respect to their particulars. Excluding the possibility of abstract universals, it becomes necessary to explain the immanent production of difference. As it turns out, object-oriented philosophy has already furnished such a theoretical resource in the concept of allure.

The idea of allure in object-oriented relations could be seen as a provocative flirtation with panpsychism. But it begins with a common enough principle in phenomenology, which is that whether or not an intentional act is structured as a fact (i.e. $x$ intends $y$ ), the experience itself bears no such structure. We do not experience features apart from their objects. So, reporting that the candy is red and rectangular superimposes a propositional character onto the experience that the experience itself does not have. This is why the theoretical relation to an object-the sundering of object and feature-figures as a separate act of will and imagination. Object-oriented philosophy generalizes this division of intention and theory to all interobject relations, not just between those of humans and objects. Thus no object, thinking or unthinking, is in direct contact with the features of another object. This generalized division of intention and theory ensures another generalized division: that between real features and sensual features. If non-thinking objects were 
in direct contact with the features of other non-thinking objects, then there would only be real features, and thus a self-same material continuum which would in turn obviate objects altogether. The presence of sensual features does just the opposite: sensual features initiate indirect contact, which necessitates a reality in which objects are primitive.

Harman defines allure as "a special and intermittent experience in which the intimate bond between a thing's unity and its plurality of [specific features] somehow partially disintegrates." ${ }^{29}$ He elsewhere describes how sensual features (or accidents) enact allure, this time with more poetic flare:

Accidents alone have the dual status of belonging and not belonging to an object, like streamers on a maypole, or jewels on a houka. Accidents are tempting hooks protruding from the sensual object, allowing it the chances to connect with others and thereby fuse two into one. ${ }^{30}$

As hooks, these sensual features diverge from their sensual object not by being severed by the intending object, but by alluding to the character of another object entirely. And in so doing, the plurality of features repeat as the unity of another sensual object, which in turn creates the possibility of a novel intention. This emergent state of belonging to one while alluding to another is aesthetic similarity in its most irreducible sense, since a plurality can never exactly resemble a unity. This is for Plato's ontological order what 666 and upside-down crosses are for Christianity: a profane inversion in which the plurality repeats as one rather than the one repeating in plurality. With allure, we have the birth of a new sensual object which presents as a contraction of sensual features emanating from another object. Yet allure is not mimetic repetition, since mimetic repetition emerges with a real object's intention of the new sensual object. Allure is the camera obscura to the silver nitrate-covered glass which records the experience. The resulting photograph is a new object. And remember that a photograph of a couch shares nothing of the couch itself.

\section{Intellectual intuition as a loose end in object-oriented philosophy}

As was pointed out at the beginning of this essay, there are two reasons for having a theory of features in the first place. The first is to explain causality and the emergence of difference (the focus of the first part of this essay). And the other is to explain and communicate the categorical differences we apprehend in our reality. The impossible dream of philosophy is that the ontology of features might somehow be reconciled with the epistemology of features. The history of philosophy is a graveyard filled with the bones of those who have tried. Yet once again, universalists have a head start in this regard. Whether by granting reality to the forms (Plato) or relations (Russell) of which we have a priori knowledge or else to law-like relations which we can observe in nature (Armstrong), knowledge and being find common cause. Trope theorists like Campbell argue that resemblance relations between particulars exist independently of thought, and even that our knowledge about which resemblances do or do not exist will not necessarily match up with those in reality. And yet there is no metaphysical explanation for why such resemblances should exist in the first place, other than the bare fact that particulars resemble. If it is simply in the nature of particulars to resemble, then their similarity is bereft of any causal power, since there would have to be some underlying production of difference. Lacking any real causal role for resemblance, one has to wonder if the motivation for positing exactly resembling particulars is in fact to account for the regularities and varieties we see in the universe. In other words, despite claims about tropes existing with or without us, it very much looks like they have been postulated for epistemic ends.

But before we come down too hard on trope theory, we may have to admit that object-oriented philosophy faces a similar problem. Through the mechanics of allure, we have seen that the intentional (sensual) object is a plurality of sensual features repeating as one, one which cannot be reverse-engineered as a plurality of

29 Ibid., 104.

30 Harman, “On Vicarious,” 218. 
eidetic features. Hence the intentional experience never exists as discrete sense data. Again, the experience itself lacks a propositional structure so that the real features of the intended object cannot be experienced directly. Which of course makes empirical knowledge impossible. Harman, like Husserl, insists that the eidetic relation-that between the sensual object and its real features (the fission of which Harman calls "theory")-is proper to intellectual intuition. ${ }^{31}$ However, Harman disagrees with Husserl that intellectual intuition of eidetic features grants us any sort of direct access to those features. But even with respect to Harman's denying intellectual intuition direct access to eidetic features, the fission of sensual object from eidetic features would still require an intellect to intuit. It would seem to be the one relation to which beings with an intellect have unique access, even if that access is not direct. This is not the same as saying that the relation between sensual object and eidetic features exists for beings with intellects, but there is a need to explain how the ontological conditions for intellectual intuition are possible even for beings without an intellect. What is needed is a mechanism analogous to allure in which the invariant features of an object allude themselves to an intending real object, whether or not that intending object is able to then think categorically about those features.

But perhaps the problem of intellectual intuition is not a problem of the intellect per se, but rather one of the will. The empiricist, for instance, does not face this problem because the qualities of an object are given as sense data. It is through repetition that sense data are contracted into objects, the being who intends remaining perfectly passive. But insofar as discrete sense data are not given (as is the case in phenomenology and object-oriented philosophy), it is necessary that the intentional object be suspended in order for its invariant qualities to be intuited. Oddly enough, one of the most bellicose voices against objectoriented ontologies, Ray Brassier, gives us a starting point for how such a suspension might work without subordinating intuition entirely to the will. Brassier's project is to formulate a realist stance on the epistemic without collapsing knowing-that into knowing-how, as some process philosophies have done. ${ }^{32}$ However, instead of falling back on a simple Cartesian mind-body dualism, Brassier holds that the void between the ontic and the epistemic is a metaphysical primitive. He argues along Platonistic lines that "otherness is distributed" among the basic modes of being: "sameness, rest and movement," and as such, "[b]eing and non-being, understood as otherness, are entwined." ${ }^{33}$ This suspension of being is relocated to the epistemic in the guise of normativity. ${ }^{34}$ So, when we put our experience of seeing the red candy into the propositional form of 'The candy is red,' we are suspending the experience of the intentional object itself, because of course the sense datum red is not given to us in a separate package. The repackaging of the object and its feature would seem to require an achievement of intellectual will. And left alone, that act of intellectual will could simply be dissolved back into the being of the thinking object. The void can be safeguarded, however, by positing that the proposition, 'The candy is red,' is in fact presupposed by the normative, 'I see that the candy is red.' The otherness that divides the red from the candy is already there in the suspension of the fact by the normative assertion that the candy is red. Rather than science having unique access to universal properties by way of fact-like natural laws, science in Brassier's reckoning has access to the corrigibility of factish statements. In so doing, science can know not just about the candy's redness but about why we should understand the candy as red in the first place, thus acquiring further insight into redness as such. Whatever else its merits, this is at least a consistent explanation for the division of intentional experience from propositional knowledge, and it demonstrates that something akin to a suspension of being is needed in order to proceed with an explanation for intuition.

While an object-oriented philosophy need not explain if or how a piece of dirt theorizes the features of a sensual object it confronts, it does need to offer explanations for the ontological conditions under which something like this is possible if it is to consistently argue that there is nothing metaphysically unique about the human-object relationship. Brassier's challenge is productive for object-oriented philosophy because it lays bare the real obstacle to a consistent object-oriented conception of the theoretical fission between a

31 Harman, Quadruple Object, 49-50.

32 Brassier, "That Which is Not," 180-181.

33 Ibid., 180.

34 Brassier, “The Which is Not,” 184. 
sensual object and its invariant features. The problem object-oriented philosophy faces here is not whether or not a thinking being should be alone among other objects in its experiencing (or performing) theoretical fission. Brassier has already provided an ontological groundwork for rationalism that does not necessarily rely on the uniqueness of human beings as a metaphysical primitive. The real ontological problem is how the being of the sensual object might be suspended for the intending object.

\section{The aesthetics of invariance}

Theoretical fission is another way of talking about eidetic reduction without the idealist baggage of Husserlian phenomenology. The basic task of eidetic reduction is to imaginatively take away all of the features of an intended object that are not essential to the object's existence. In other words, what you're really looking for in eidetic reduction are the invariant features of the object. Apprehending the invariant features means entering the particular features of a particularly experienced object into a general system of knowledge. The classical example here is Descartes's ball of wax. Many things about the wax will change when it is melted, but the things that make it a body, such as extension and mass, remain. Phenomenology tends to be more liberal in the invariants it admits, but the idea is more or less the same. The key to reducing variants to invariants is what Husserl calls "eidetic division," which is to introduce a part-whole dialectic into the eidetic relation..$^{35}$ We can otherwise talk about this in terms of determinates and determinables. For example, my watermelon Jolly Rancher is a particular kind of red exactly resembling no others. But let's just call it amaranth. Amaranth is a determinable of the particular determinate color of the candy, and red is a determinable of the determinate amaranth. Each time we perform this eidetic division from determinate to determinable, we are displacing negative content, or moving the void further along. Red itself can be the determinate of color; and here, presumably, invariance is pushed to its absolute limit: there is either color or no color, being and non-being. This is what suspension of being ultimately looks like to the phenomenologist. It is this suspension of being that is presupposed in any exercise of eidetic reduction. But if we admit this account of eidetic reduction into object-oriented philosophy's theoretical fission-that is, if we admit it into inter-object relations in general-then object-oriented philosophy becomes a species of Badiouan set ontology, with the void as its operating principle.

Another way to handle this march to non-being through eidetic reduction is to say that instead of displacing negative content in the determinate-to-determinable operation, we are actually interiorizing positive content which in turn produces the appearance of an invariant exterior. This would be an aesthetic rather than a logical operation. The most basic place to begin this line of thinking is in the distinction between place and space. We can logically say that place is a determinate of space. And that works very well if you're teaching the concept of place to someone who only has a concept for space. But we cannot in reality say that a real place is reducible to space. If you're in a kitchen, for instance, you cannot say that the kitchen-place is composed of the space there between the vent and the stove, the space there between the refrigerator and the wall, et cetera, et cetera. All you're doing in that case is identifying other places. You are, in fact, interiorizing positive content. A place is where something is; a space is between things where something is not. There is no need to press this line of argument into a declaration about the true nature of space. What's important here is place. A place is a thing with something in its interior, but it is also a thing, an object itself. The sensual object of a particular place is many features repeated as a unity through the work of allure. But the ontological disposition out of which the propositional content, 'This place is a space,' can be generated must be quite different from allure. In fact, it has to be more or less the opposite of allure if what we're doing is orientating the intending object towards the division of features from other objects.

What must be remembered is that only sensual objects are directly intended; features are not. However, several sensual objects, according to Harman, may enter into a field of experience, for which the intending 
real object acts as a bridge. ${ }^{36}$ The intending object may enter into a relation of affective sincerity ${ }^{37}$ with a particular sensual object, in which a new intention-object emerges. This emergence I have argued is the method actor's mimesis. But perhaps sincerity need not always work this way. One of the most notable instances of world-building in the film The Matrix is when the sagely Morpheus tells the hero Neo that the experience of déjà $v u$ is in fact a glitch in the virtual world of the matrix. Déjà vu is of course the uncanny repetition of a moment. What I have in mind here can be a spatial glitch as well as a temporal glitch. Not being an expert on The Matrix universe, I can only imagine that the glitch in the matrix is a line of code that's been spliced together, not unlike a bit of film poorly spliced, wherein for a split second, one frame consists of two overlapping frames. The effect of this is to call attention to the medium of the film or the matrix: celluloid or code. The medium has been exteriorized as a self-same continuum exterior to the interiorized positive content of the intentional object. Indeed, this is not a bad definition for matter as well as medium, matter and medium being often conflated in the discourse of art. What is called 'matter' or 'medium' is nothing more or less than an experiential contraction of an intended object's invariant features. This is true too in our basic example of place and space. Perhaps you've had a poster of the Cliffs of Moher in western Ireland on your wall for years. Then you finally get the chance to go and see the place for real. Coming upon it at roughly the same angle as your poster displays, you're suddenly overwhelmed by a sense of spatial déjà $v u$. You become far more aware of the place's extension, the gradient of the path leading to the edge, and the sheer drop to the sea than you ever would have been if you had never seen the vista before, impressive though it may be. In this case, you as the intending object beholding the cliffs for (not) the first time find yourself in the position of the intention-object that emerges from the sincere relation of an intending (real) object and an intended (sensual) object. The features of the actual cliffs-the gradients and spatial extension-become the exteriorized remainder in this sensuous repetition. Space appears as a medium of continuity against the singularity of the experience of the place. And perhaps the opposite happens when you return home to your poster. This is not eidetic reduction itself but an aesthetic starting point for the exteriorizing suspension of being necessary for an intellect to proceed with eidetic reduction.

All of what has just been described will be familiar to anyone acquainted with the psychology of the uncanny. Freud takes Schelling's account of the uncanny (Unheimlich) as that which "ought to have remained hidden and secret, yet comes to light," and introduces the notion of the double. ${ }^{38}$ The horror of seeing one's own uncanny double is, for Freud, evidence of a faculty "which is able to treat the rest of the ego like an object [...]." 39 The identity crisis in encountering the double, Freud argues, allows for a suspension of identity so that new meaning can be invested into one's own ego, not unlike the toddler who suspends her own being-with-the-world in Gestalt psychology. Julia Kristeva perhaps best describes the aesthetic conditions for the uncanny in her work on the horror of abjection. The abject may be anything from excrement to cadavers, but experiences with these things share the common trait of a threat to the interior of what has been exteriorized:

If dung signifies the other side of the border, the place where I am not and which permits me to be, the corpse, the most sickening of wastes, is a border that has encroached upon everything. It is no longer I who expel, 'I' is expelled. The border has become an object. How can I be without a border? ${ }^{40}$

This echoes Kant's thoughts in Critique of Judgement on the disgusting. There Kant argues that evil things could be rendered beautiful just as well as good things could. The disgusting, however, always exists in a zone beyond the beautiful, always threatening to invade our imagination: "the object is represented as

36 Harman, Quadruple Object, 108.

37 Sincerity is the term Harman uses to describe a state in which the intending object is absorbed with the intended object, which is more intense than an intended object simply crossing into the intending object's field of experience. See Harman, "On Vicarious," 199.

38 Freud, “The Uncanny," 4.

39 Ibid., 10.

40 Kristeva, Powers, 3-4. 
it were obtruding itself for our enjoyment, while we strive against it with all our might." ${ }^{\prime 11}$ As an artistic representation, "the object is no longer distinguished from the nature of the object itself in our sensation, and thus it is impossible that it can be regarded as beautiful." ${ }^{42}$ Already in Kant, we see the invasion of what has been exteriorized and the horror of the double. The disgusting cannot be beautiful precisely because its stark similarity to nature suspends the artifice, leaving what appears to be bare materiality-or that which is invariant-as its remainder. The invariant nature of the object represented threatens to destroy the existence of the representational art object.

What is common to the sublime experience of seeing the Cliffs of Moher and the encounter with the corpse is that the one sensual object with which we are sincerely engaged repeats as a plurality of objects. Yet this plurality is not the usual continuity of sensual objects that the intending real object bridges. The repetition of the one as the many in the sublime and the uncanny is a suspension of the unified sensual object with which the real object is engaged. As such, it is an allusion to the sensual object's eidetic features. Although the thinking being may engage in eidetic reduction from there, the eidetic divisionwhat we might now recast as theoretical fission-is already there at the aesthetic, inter-object level. It is true that all of the examples given in the previous section have illustrated human experiences; however, if we take aesthetic causality to be, as object-oriented philosophy does, a metaphysical primitive, then there is no need at this juncture to speculate on how, for instance, theoretical fission occurs for a Jolly Rancher encountering a concrete wall. Nor does theoretical fission need to occur in the extreme instances of the sublime or the uncanny. Scientific modeling would seem to be a clear instance of the one repeating as the multiple. Whereas the apparent remainder of invariant features in repetition means for Kant a failure of artistic representation, it becomes the very basis of a successful scientific model.

\section{Conclusion}

In a rare display of pathos, Wilfrid Sellars once argued that the abandonment of the Thomistic isomorphism of being and being known was "a cancer at the heart of modern philosophy." ${ }^{33}$ To abandon any version of that isomorphism, Sellars thought, was to begin the march towards either idealism or skepticism, complimentary pictures of reality in which the things of this world conform to our ideas of them or else our ideas about the world are all we are capable of explaining. Committing to a reality of discrete substances (e.g. objects) which fundamentally do not operate according to any further principle of division (i.e. the transcendence of natural law) gives us firm footing against the slide into idealism and skepticism. However, a realist metaphysics must also account for the repetition of regular divisions as well as how it is possible for objects to experience those divisions. In order to do so, it is necessary to be a realist about similarity. As such, the notion that similarity simply stands in for partial sameness between particulars must be discarded in favor of the view that real objects imitate what affects them as the invariant features of the sensual objects with which they interact. From a long enough view, these repetitions of the similar enfold and operate as regularity, even as invariance remains in the realm of sensual experience.

\section{References}

Aristotle. The Works of Aristotle: De Amina. Translated by J.A. Smith. Oxford: Clarendon Press, 1931. Armstrong, David Malet. What is a Law of Nature? Cambridge: Cambridge University Press, 2016. Kindle edition. Armstrong, David Malet. Nominalism and Realism v. 1: Universals and Scientific Realism. Cambridge: Cambridge University Press, 1978.

Brassier, Ray. "That Which is Not: Philosophy as Entwinement of Truth and Negativity." Stasis. No. 1 (2013), 174-186. Campbell, Keith. Abstract Particulars. Oxford: Oxford University Press, 1990. Edwards, Douglas. Properties. Cambridge: Polity Press, 2014. Kindle Edition.

41 Kant, Critique, §48 (emphasis mine).

42 Ibid.

43 Sellars, Science, loc. 920. 
Freud, Sigmund. “The Uncanny.” Translated by Alix Strachey. Massachusetts Institute of Technology Online Library, 1919. Accessed July 30, 2018. http://web.mit.edu/allanmc/www/freud1.pdf

Goodman, Nelson. "Seven Strictures on Similarity.” In Problems and Projects, edited by Nelson Goodman and W.V.O. Quine, 437-446. Indianapolis: Bobs-Merrill Co., 1972.

Harman, Graham. Dante's Broken Hammer: The Ethics, Aesthetics, and Metaphysics of Love. London: Repeater Books, 2016. Kindle edition.

Harman, Graham. "Materialism is Not the Solution: On Matter, Form, and Mimesis." The Nordic Journal of Aesthetics. No. 47 (2014), 94-110.

Harman, Graham. The Quadruple Object. Winchester, UK: Zero Books, 2011.

Harman, Graham. “On Vicarious Causation.” Collapse. V. 2 (2007), 171-206.

Husserl, Edmund. Ideas: General Introduction to Pure Phenomenology. Translated by W.R. Boyce Gibson. New York: Macmillan, 1931.

Kant, Immanuel. The Critique of Judgement. Translated by J.H. Bernard. New York: Hafner Press, 1951.

Kristeva, Julia. The Powers of Horror: An Essay on Abjection. Translated by Leon S. Roudiez. New York: Columbia University Press, 1982.

Morreau, Michael. “It Simply Does Not Add Up: Trouble with Overall Similarity.” The Journal of Philosophy. V. 107, No. 9 (2010), 469-490.

Plato. Timaeus. Translated by Peter Kalkavage. Bemidji, MN: Focus Publishing, 2001.

Plato. Meno. Translated by George Anastaplo and Laurence Berns. Bemidji, MN: Focus Publishing, 1998.

Plato. The Republic (2 ${ }^{\text {nd }}$ Edition). Translated by Alan Bloom. New York: Basic Books, 1991.

Russell, Bertrand. The Problems of Philosophy. Urbana, IL: Project Gutenberg, 2009. Accessed July 30, 2018. http://www.gutenberg.org/ebooks/5827

Sellars, Wilfrid. Science, Perception and Reality. Austin, TX: Ridgeview Publishing Digital, 1991. Kindle edition.

Williams, Donald C. The Elements and Patterns of Being: Essays in Metaphysics. Oxford: Oxford University Press, 2018. 